\title{
Chromatographic Release Profile of Active Pharmaceutical Ingredients of Synthesized Prodrug and Codrug of Aspirin+Paracetamol and Indomethacin+Paracetamol in Physiological Fluids
}

\section{Debojyoti Basu, Divyesh Sharma and Dr Dhrubo Jyoti Sen*}

Date of Receipt- 02/o8/2017
Date of Revision- 18/08/2017

Date of Acceptance- 26/08/2017

\section{Address for}

Correspondence

Department of Pharmaceutical Chemistry, Shri Sarvajanik

Pharmacy College,

Gujarat Technological

University, Arvind Baug, Mehsana-384001, Gujarat, India

E-mail: dhrubosen69@yahoo.com

\section{ABSTRACT}

Prodrug is the precursor of drug which is made by derivatization of the same to enhance the bioavailability by pharmacokinetics, lipid solubility by partition coefficient and increase the physicochemical and biochemical parameters by pharmacodynamics. All two prodrugs showed different $\log$ P values and molecular weights according to the solubility parameters and electronegativity: $\log P$ profile: Prodrug-B $>$ Prodrug-A; molecular weight profile: Prodrug-B $>$ Prodrug-A.

The main side effect of NSAID is gastric acidity due to release of free $\mathrm{H}+$ because all NSAIDs have free- $\mathrm{COOH}$ (carboxylic acid) group which act by competitive inhibition of cyclooxygenase enzyme (COX1/COX2). Here the target of this project has been designed in such a way to convert the free $-\mathrm{COOH} /-\mathrm{OH}$ of API (aspirin/paracetamol) into prodrug of two ester (-COO-) and one amide ($\mathrm{CONH}-$ ) linkage (Prodrug-A) and one ester and two amide linkage (Prodrug-B) which releases free API after metabolic hydrolysis in acidic $\mathrm{pH}$ : 1-4 and alkaline $\mathrm{pH}$ : 7-9. Since the prodrugs are repository forms so chances to release gastric acid has been minimized due to non-availability of free- $\mathrm{COOH}$ group in stomach. The biotransformation of active drug from prodrug takes such a time in stomach that all goes upto duodenum and then ileum of small intestine that chances of acidity is reduced. Finally all prodrugs go to small intestine where alkaline $\mathrm{pH}$ starts so gastric acidity is reduced. Since all two prodrugs are made of two NSAID: Prodrug-A $(\log \mathrm{P}=2.15)$ releases Aspirin and Paracetamol, Prodrug-B $(\log \mathrm{P}=3.94)$ releases Indomethacin and Paracetamol which shows distinct two Rt values in HPLC both in acidic an alkaline hydrolysis and these Rt values of Prodrugs match with the individual API components so the purpose of our goal has been completed successfully. The $\mathrm{pH}$ of gastric acid varies from 1.53.5 in the human stomach lumen, the acidity being maintained by the proton pump $\mathrm{H}+\mathrm{K}+$ ATPase. So the pattern for acid hydrolysis was adjusted at $\mathrm{pH}=3$ 3.5 by $\mathrm{HCl}$. The $\mathrm{pH}$ of intestine varies from 5.6-6.9, so the pattern for alkaline hydrolysis was adjusted at $\mathrm{pH}=7.0-8.0$ by $\mathrm{NaOH}$. In case of codrug which is made by non-covalent interactions such as hydrogen bonding, ionic interactions, Van der Waals interactions and $\pi$-interactions between two APIs, so the release of parent molecule will be faster than prodrug both in acidic as well as in alkaline $\mathrm{pH}$ because prodrug is made by covalent bonding between two APIs.

$\log$ P profile: Codrug-B (3.42)>Codrug-A (1.55); molecular weight profile: Codrug-B (508.94g) > Codrug-A (331.31g).

Keywords: API, Mobile phase, Rt-HPLC, Covalent bond, Acidic hydrolysis, Alkaline hydrolysis, Hydrogen bonding, Ionic interactions, Van der Waals interactions, $\pi$-interactions. 


\section{INTRODUCTION}

\section{Hydrolysis Pattern of Prodrug-A}

Ester linkage of Prodrug-A is ruptured by acid/ alkali to free API (Aspirin and Paracetamol) by hydrolytic cleavage (Figure 1).

Esters and amides are two linkages which are hydrolysable to produce two separete entities. Esters produce carboxylic acid moiety $(-\mathrm{COOH})$ and alcohol/phenol moiety $(-\mathrm{OH})$ whereas amides produce carboxylic acid $(-\mathrm{COOH})$ and amino moiety $\left(-\mathrm{NH}_{2}\right)$. Nitriles or cyanides ($\mathrm{CN}$ ) are also hydrolysable group but this is not a linkage but this is a functional group attached at the end terminal which is hydrolysed into carboxylic acid $(-\mathrm{COOH})$ and free amino group $\left(-\mathrm{NH}_{2}\right)$. Hydrolysis is possible in acidic and alkaline medium which ruptures the linkages to produce the desired moiety.

Our prodrug is formed by covalent bonding between two APIs to produce Prodrug-A made by aspirin and paracetamol which produce two ester and one amide linkage whereas Prodrug-B is made by indomethacin and paracetamol which produce one ester and two amide linkages ${ }^{1,2}$.

\section{Hydrolysis Pattern of Prodrug-B}

Ester linkage of Prodrug-B is ruptured by acid/alkali to free API (Indomethacin and Paracetamol) by hydrolytic cleavage (Figure 2).

Actually acyl [-O-CO-] and ester [- $\left.\mathrm{CO}_{-}-\mathrm{O}_{-}\right]$ both have same linkages so Prodrug-A have two ester and one amide linkages so $\log \mathrm{P}=2.15$ whereas Prodrug-B has one ester [ $-\mathrm{CO}-\mathrm{O}-]$ and two amide [-CO-NH-] linkages so $\log \mathrm{P}=3.94$, because the ester and amide both are susceptible for hydrolysis but in amide $(-\mathrm{CONH}-)$ three lone pairs of electrons are present (two for oxygen and one for nitrogen) and in ester ($\mathrm{COO}-$ ) four lone pairs of electrons are present (four for two oxygen). So the electron density of ester is greater than amide and electronegativity of oxygen is 3.44 and for nitrogen is 3.04 . So total electronegativity of ester $(-\mathrm{COO}-)$ is $3.44+3.44=6.88$ and for amide $(-\mathrm{CONH}-)$ is $3.44+3.04=6.44$. Hence ester is more susceptible for hydrolysis compared to amide.

\section{Release Pattern of Codrug-A}

Non-covalent interactions such as hydrogen bonding, ionic interactions, Van der Waals interaction and $\pi$-interaction are ruptured to release free API (Aspirin and Paracetamol) during hydrolytic cleavage (Figure 3).

Lone pair profile: Ester $>$ Amide and Electronegativity profile: Ester $>$ Amide. In this case Prodrug-A: two ester and one amide, so lone pair profile: $4 \times 2=6$ for ester and 3 for amide; hence 6 (ester electronegativity) $>3$ (amide electronegativity) for Prodrug-A (ester is greater than amide so $\log P$ is 2.15 ). In case of Prodrug-B: one ester and two amide, so lone pair: 4 for ester and $3 \times 2=6$ for amide; hence 6 (amide electronegativity) $>4$ (ester electronegativity) for Prodrug-B (Amide is greater than ester so $\log \mathrm{P}$ is 3.94). Hence Prodrug- $B$ is more nonpolar than Prodrug- $\mathrm{A}^{3,4}$.

\section{Release Pattern of Codrug-B}

Non-covalent interactions such as hydrogen bonding, ionic interactions, Van der Waals interactions and $\pi$-interactions are ruptured to release free API (Indomethacin and Paracetamol) during hydrolytic cleavage (Figure 4).

Prodrug-A and Prodrug-B both have ester linkages which is ruptured in acidic and alkaline $\mathrm{pH}$ into two different moieties. Prodrug-A produces aspirin and paracetamol and Prodrug-B produces indomethacin and paracetamol. These two products produce two peaks at HPLC to show different $\mathrm{R}_{t}$ values according to their polarity followed by $\log$ P: Aspirin (1.19), Indomethacin (3.10) and Paracetamol (0.34). Since the prodrugs are made by covalent linkages of esters and amides so it takes some time to be ruptured into desired API according to the polarity whereas in Codrug-A and Codrug-B which are made by noncovalent interactions such as hydrogen bonding, ionic interactions, Van der Waals interactions and $\pi$-interactions between two APIs, so the release of parent molecule is faster than prodrug both in acidic as well as in alkaline $\mathrm{pH}$ because prodrug is made by covalent bonding between two APIs ${ }^{5-7}$.

\section{Selection of Ratio of Mobile Phase}

The solution containing $100 \mu \mathrm{g} / \mathrm{ml}$ of Prodrug-A, Prodrug-B, Codrug-A and Codrug-B respetively was chromatographed with mobile phase of different ratio of methanol and water.

\section{EXPERIMENTAL}

Reagents and Materials, Prodrug-A synthesized in our college lab, Methanol (HPLC grade, Finar Chemicals Ltd, Ahmedabad, India), Water 
(HPLC grade, Finar Chemicals Ltd, Ahmedabad, India).

\section{Equipments and Instruments}

Shimadzu HPLC instrument (LC-2010 CHT) equipped with prominence diode array detector (SPD-M20A) (Software LC Solution), Analytical balance (Acculab ALC-2014, Huntingdon Valley, PA), Ultra sonicator (EN 30 US, Enertech Fast Clean, Mumbai, India), Hot air oven (TO-90S, Thermolab, Mumbai, India), $\mathrm{pH}$ meter (Thermo Electron Corp., Pune, India) (Table 1).

A. Aspirin profile: Standard aspirin at $284 \mathrm{~nm}$ in mobile phase ACN: Triethylamine buffer (50:50 $\mathrm{v} / \mathrm{v})$ :- $(\log \mathrm{P}=1.19)$. Aspirin releases moderately slow $\left(\mathrm{R}_{\mathrm{t}}=2.3 \mathrm{~min}\right)$ because it's $\log \mathrm{P}$ is 1.19 (semipolar) (Figure 5).

B. Indomethacin profile: Standard Indomethacin peak at $278 \mathrm{~nm}$ in mobile phase Water: ACN $(80: 20 \mathrm{v} / \mathrm{v}):-(\log \mathrm{P}=3.10)$. Indomethacin releases slow $\left(\mathrm{R}_{\mathrm{t}}=5.5 \mathrm{~min}\right)$ because it's $\log \mathrm{P}$ is 3.97 (nonpolar) (Figure 6).

C. Paracetamol profile: Standard paracetamol peak at $230 \mathrm{~nm}$ in mobile phase. Phosphate Buffer: ACN $(40: 60 \quad \mathrm{v} / \mathrm{v})$ :- $\quad(\log \mathrm{P}=0.34)$. Paracetamol releases first $\left(\mathrm{R}_{\mathrm{t}}=2 \mathrm{~min}\right)$ because it's $\log \mathrm{P}$ is 0.34 (highly polar) (Figure 7).

Prodrug-A Profile $(\log \mathrm{P}=2.15)$

Prodrug-A has $\log \mathrm{P} 2.15$ so it releases slowly $\left(\mathrm{R}_{\mathrm{t}}=5.5 \mathrm{~min}\right.$ ) due to nonpolar nature (Figure 8).

Paracetamol has $\mathrm{R}_{\mathrm{t}}=2.75 \mathrm{~min}$ in acidic medium and 2.8 min in alkaline medium; aspirin has $\mathrm{R}_{\mathrm{t}}=4$ min in acidic medium and $3.8 \mathrm{~min}$ in alkaline medium (Figure 9).

Prodrug-B Profile $(\log \mathrm{P}=3.94)$

Prodrug- $\mathrm{B}$ has $\log \mathrm{P} 3.94$ and $\mathrm{R}_{\mathrm{t}}=6.8 \mathrm{~min}$ so release rate is low (Figure 10).

Paracetamol has $\mathrm{R}_{\mathrm{t}}=2.5 \mathrm{~min}$ in acidic medium and $3.5 \mathrm{~min}$ in alkaline medium; indomethacin has $R_{t}=6.35 \mathrm{~min}$ in acidic medium and $6.15 \mathrm{~min}$ in alkaline medium (Figure 11).

\section{Codrug-A Profile}

Codrug-A has $\log \mathrm{P} 1.55$ so it releases fast due to polar nature. Codrug- $\mathrm{A}$ has $\log \mathrm{P} 1.55$ so it is polar in nature so it shows $\mathrm{R}_{\mathrm{t}}=3.4$ mins (Figure 12).

Paracetamol has $\mathrm{R}_{\mathrm{t}}=2.75 \mathrm{~min}$ in acidic medium and $2.8 \mathrm{~min}$ in alkaline medium; aspirin has $\mathrm{R}_{\mathrm{t}}=4$ min in acidic medium and $3.8 \mathrm{~min}$ in alkaline medium (Figure 13).

\section{CODRUG-B PROFILE}

Codrug-B has $\log \mathrm{P} 3.42$ so it releases slow due to nonpolar nature.

Prodrug-B is highly nonpolar so it releases at $\mathrm{R}_{\mathrm{t}}$ 6.8 min (Figures 14 and 15).

Paracetamol has $\mathrm{R}_{\mathrm{t}}=3.4 \mathrm{~min}$ in acidic medium and $3.4 \mathrm{~min}$ in alkaline medium; indomethacin has $\mathrm{R}_{\mathrm{t}}=6.8 \mathrm{~min}$ in acidic medium $6.35 \mathrm{~min}$ in alkaline medium (Figures 16 and 17).

\section{CONCLUSION}

\section{API Profile}

Aspirin releases moderately slow $\left(\mathrm{R}_{\mathrm{t}}=3.3\right.$ min) because it's $\log \mathrm{P}$ is 1.19 (semipolar). Indomethacin releases slow $\left(\mathrm{R}_{\mathrm{t}}=6.8 \mathrm{~min}\right)$ because it's $\log \mathrm{P}$ is 3.97 (nonpolar). Paracetamol releases first $\left(\mathrm{R}_{\mathrm{t}}=2.5 \mathrm{~min}\right)$ because it's $\log \mathrm{P}$ is 0.34 (highly polar).

Codrug-A has $\log \mathrm{P} 1.55$ so it is polar in nature so it shows Rt=1.8 mins (Figure 12).

Prodrug Profile

Prodrug-A has $\log \mathrm{P} 2.15$ so it releases slowly due to nonpolar nature. Prodrug-A has $\mathrm{R}_{\mathrm{t}}=5.5$ min. Paracetamol has $\mathrm{R}_{\mathrm{t}}=2.75 \mathrm{~min}$ in acidic medium and $2.8 \mathrm{~min}$ in alkaline medium; Aspirin has $R_{t}=4$ min in acidic medium and $3.8 \mathrm{~min}$ in alkaline medium. Prodrug- $B$ has $R_{t} 6.8 \mathrm{~min}$. Prodrug-B has $\log \mathrm{P} 3.94$ so release rate is slower. Paracetamol has $R_{t}=2.5 \mathrm{~min}$ in acidic medium and $3.5 \mathrm{~min}$ in alkaline medium; Indomethacin has $\mathrm{R}_{\mathrm{t}}=6.35 \mathrm{~min}$ in acidic medium and $6.15 \mathrm{~min}$ in alkaline medium.

\section{Codrug Profile}

Codrug- $\mathrm{A}$ has $\mathrm{R}_{\mathrm{t}}=3.4 \mathrm{~min}$ and $\log \mathrm{P} 1.55$. Paracetamol has $R_{t}=2.75 \mathrm{~min}$ in acidic medium and 2.8 min in alkaline medium; Aspirin has $R_{t}=4$ min in acidic medium and $3.8 \mathrm{~min}$ in alkaline medium. Codrug-B has $\log \mathrm{P} 3.42$. Paracetamol has $R_{t}=3.4$ min in acidic medium and $3.4 \mathrm{~min}$ in alkaline medium; Indomethacin has $\mathrm{R}_{\mathrm{t}}=6.8 \mathrm{~min}$ in acidic medium $6.35 \mathrm{~min}$ in alkaline medium.

$\log P$ profile: Prodrug-B (3.94) $>$ Codrug-B (3.42) > Prodrug-A (2.15)>Codrug-A (1.55).
$\mathbf{R}_{\mathrm{f}}$ profile: Prodrug-B
(5.6) $>$ Indomethacin
(4.8) $>$ Codrug-A
(6.2) $>$ Codrug-B
(5.2) $>$ Prodrug-A
(3.7) $>$ Paracetamol (2.8). 
$\mathbf{R}_{\mathbf{t}}$ profile: Prodrug-B (6.8 $\left.\mathrm{min}\right)>$ Codrug-B (6.38 $\mathrm{min})>$ Indomethacin $(5.5 \mathrm{~min})>$ Prodrug-A $(5.5 \mathrm{~min})>$ Codrug-A $(3.4 \mathrm{~min})>$ Aspirin $\quad(2.3$ min) $>$ Paracetamol ( $2 \mathrm{~min}$ ).

\section{ACKNOWLEDGEMENT}

The authors Debojyoti Basu and Divyesh Sharma both students of B.Pharm-V at Shri Sarvajanik Pharmacy College, Mehsana did this project under the esteemed guidance of Prof. Dr. Dhrubo Jyoti Sen. This project is fully based on basic chemical science including physical synthesis (codrug) as well as chemical synthesis (prodrug) and instrumental analysis through elemental analysis, chromatography of drug followed by API, CHN\%, Prodrug, Codrug, Co-crystallization, $\log \mathrm{P}, \mathrm{TLC}, \mathrm{UV} \lambda_{\max }$, IR Spectra, Mass Spectra, Hydrogen bonding, Ionic interactions, Van der Waals interactions, $\pi$-interactions.

Chromatographic release profile of active pharmaceutical ingredients of synthesized prodrug and codrug of aspirin + paracetamol and indomethacin + paracetamol in physiological fluids is the outcome of the total efforts and applications of B.Pharm. course contents into practical approach. The authors are thankful to Shri Sarvajanik Pharmacy College, Mehsana for providing drugs and laboratory facilities to perform synthesis of prodrug and codrug with their analytical profiles to fulfill this project with grand success. The authors are thankful to quality assurance lab of Shri Sarvajanik Pharmacy College, Mehsana for TLC and HPLC studies respectively.

\section{REFERENCES}

1. Patel JG, Sen DJ. Synthesis of Prodrug of ester and amide linkages of NSAID having carboxylic acid, phenolic and imino groups.
World J Pharm Pharm Sci. 2016;5(11):897908.

2. Sen DJ, Patel JG. Logarithmic partition coefficient comparison study and molecular weight of synthesized Prodrugs of ibuprofen+paracetamol, diclofenac sodium+paracetamol and ibuprofen+diclofenac sodium. Am J Drug Deliv. 2016;4(5):64-8.

3. Sen DJ. Correlation approach of in-vivo and in-vitro hydrolytic metabolism of ester linkage of prodrug made of indomethacin and paracetamol in RP-HPLC in acidic and alkaline medium: European Journal of Biomedical and Pharmaceutical Science. 2017;4(7):424-33.

4. Sen DJ. RP-HPLC study of in-vitro biotransformation of prodrugs of ester and amide linkages of ibuprofen, diclofenac sodium and paracetamol in acidic and alkaline medium. Pharma Tutor. 2017;5(8):49-65.

5. Gediya PA, Sen DJ. Co-crystallization technology: A magic bullet in medicinal chemistry. International Journal of Advances in Pharmaceutical Research. 2013;4(8):207176.

6. Akhani $\mathrm{P}$, Thakkar $\mathrm{A}$, Shah $\mathrm{H}$, et al. Correlation approach of prodrug and codrug in biotransformation. European Journal of Pharmaceutical and Medical Research. 2017;4(5):488-500.

7. Basu D, Sharma D, Sen DJ. Comparative physicochemical correlation study of synthesized prodrug and codrug of aspirin+paracetamol and indomethacin+paracetamol by covalent and non-covalent bonding. World J Pharm Res. 2017;6(8):2066-83. 


\begin{tabular}{|c|c|c|c|c|c|c|c|}
\hline \multirow{7}{*}{$\begin{array}{c}\text { Prodrug-A/ } \\
\text { Codrug-A }\end{array}$} & Trials & Ratio & Remark & \multirow{7}{*}{$\begin{array}{c}\text { Prodrug-B/ } \\
\text { Codrug-B }\end{array}$} & Trials & Ratio & Remark \\
\hline & 1 & $\begin{array}{c}\text { Methanol: Water } \\
(60: 40)\end{array}$ & Tailing & & 1 & $\begin{array}{c}\text { ACN: Water } \\
(80: 20)\end{array}$ & Tailing \\
\hline & 2 & $\begin{array}{c}\text { Methanol: Water } \\
(70: 30)\end{array}$ & Tailing & & 2 & $\begin{array}{c}\text { ACN: Water } \\
(70: 30)\end{array}$ & Tailing \\
\hline & 3 & $\begin{array}{c}\text { ACN: Water } \\
(60: 40)\end{array}$ & Tailing & & 3 & $\begin{array}{l}\text { ACN: Methanol } \\
\quad(80: 20)\end{array}$ & Tailing \\
\hline & 4 & $\begin{array}{c}\text { ACN: Water } \\
(70: 30)\end{array}$ & Tailing & & 4 & $\begin{array}{c}\text { ACN: Methanol } \\
(70: 30)\end{array}$ & Tailing \\
\hline & \multirow[t]{2}{*}{5} & $\begin{array}{c}\text { Methanol: Water } \\
(80: 20)\end{array}$ & \multirow[t]{2}{*}{$\begin{array}{c}\text { Symmetrical } \\
\text { peak }\end{array}$} & & 5 & $\begin{array}{c}\text { Methanol: Water } \\
(80: 20)\end{array}$ & Tailing \\
\hline & & & & & 6 & $\begin{array}{l}\text { Methanol: Water } \\
\quad(70: 30)\end{array}$ & $\begin{array}{c}\text { Symmetrical } \\
\text { peak }\end{array}$ \\
\hline
\end{tabular}

Table 1. Selection of mobile phase for Prodrug-A, Prodrug-B, Codrug-A and Codrug-B

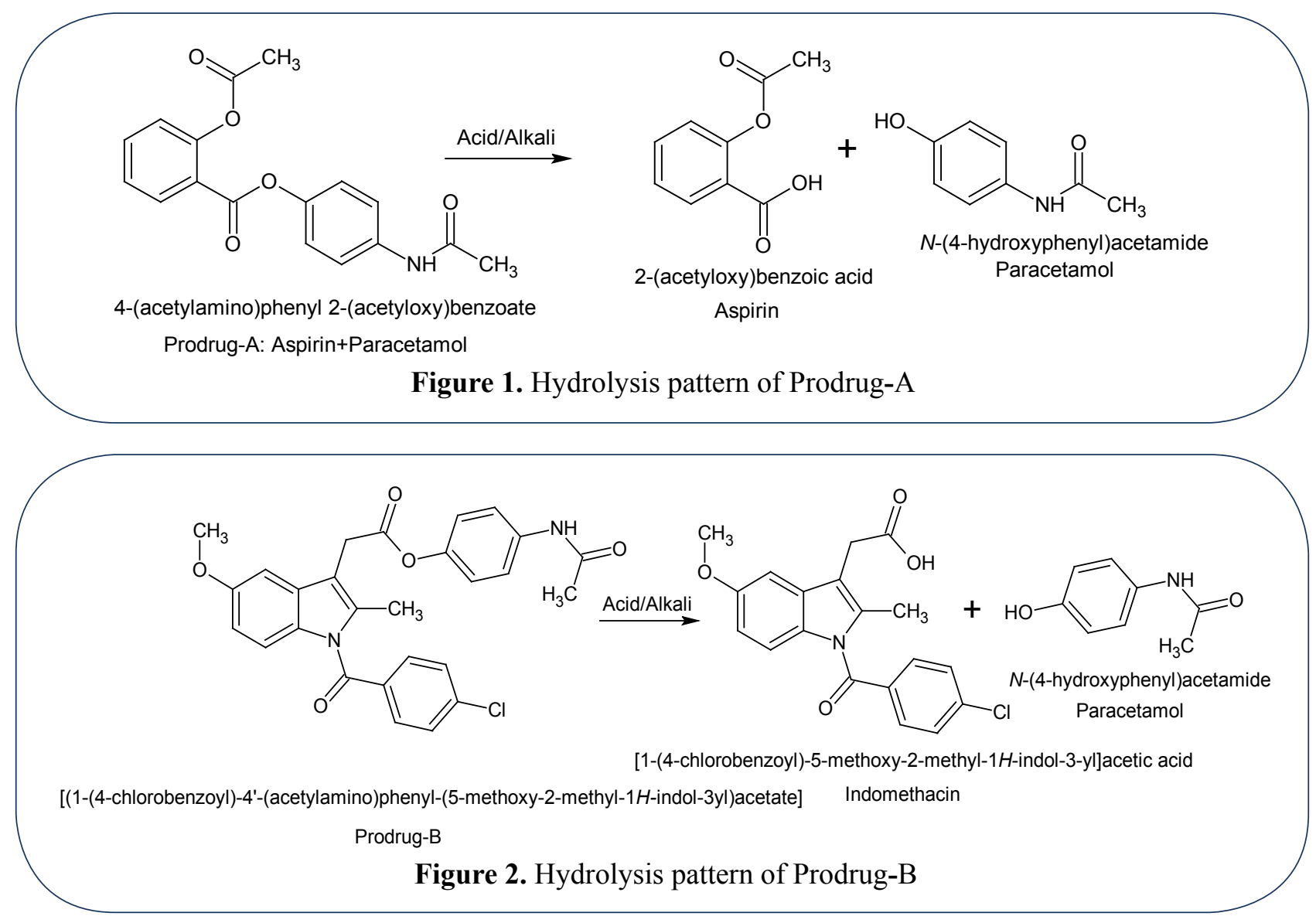




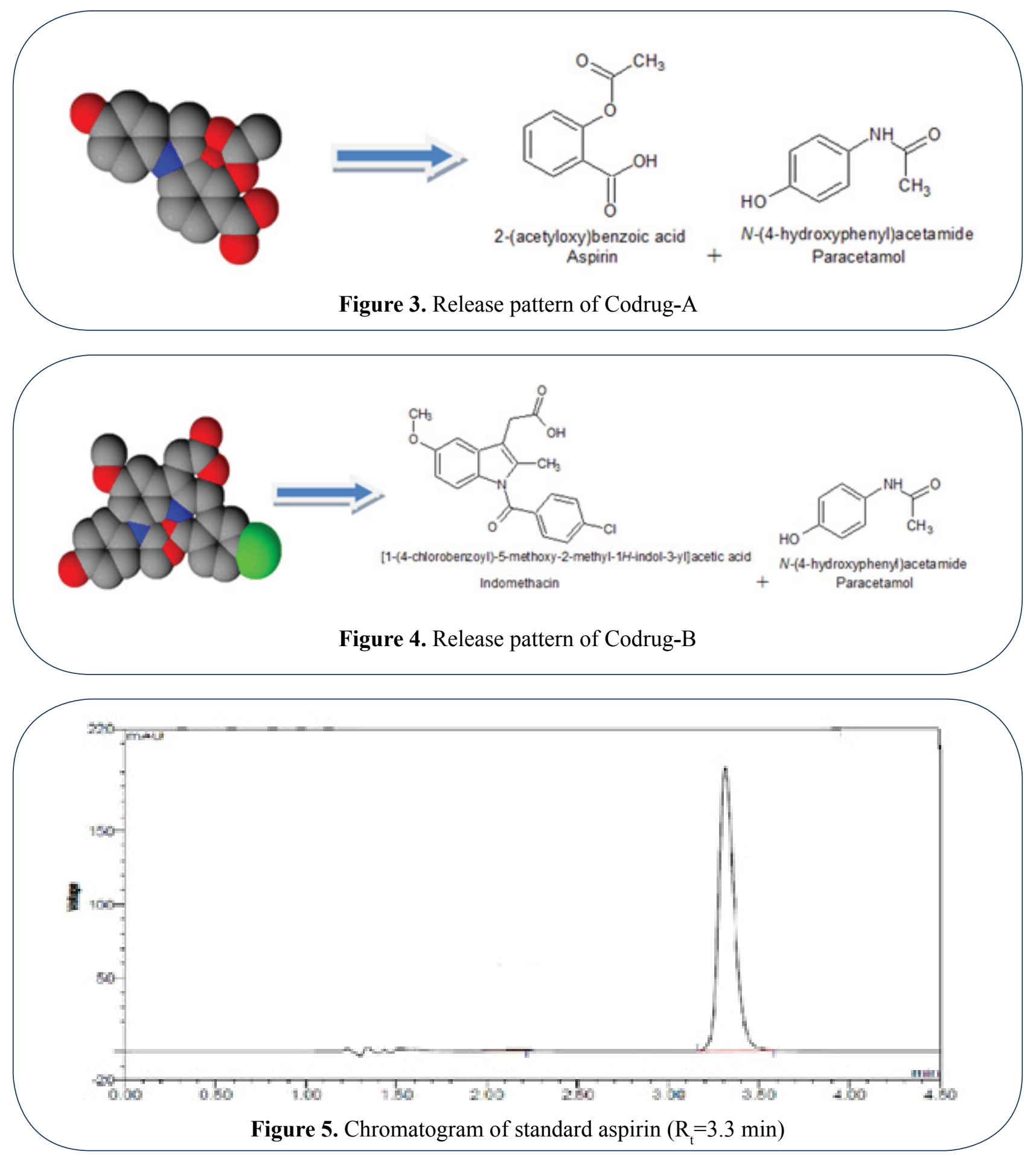



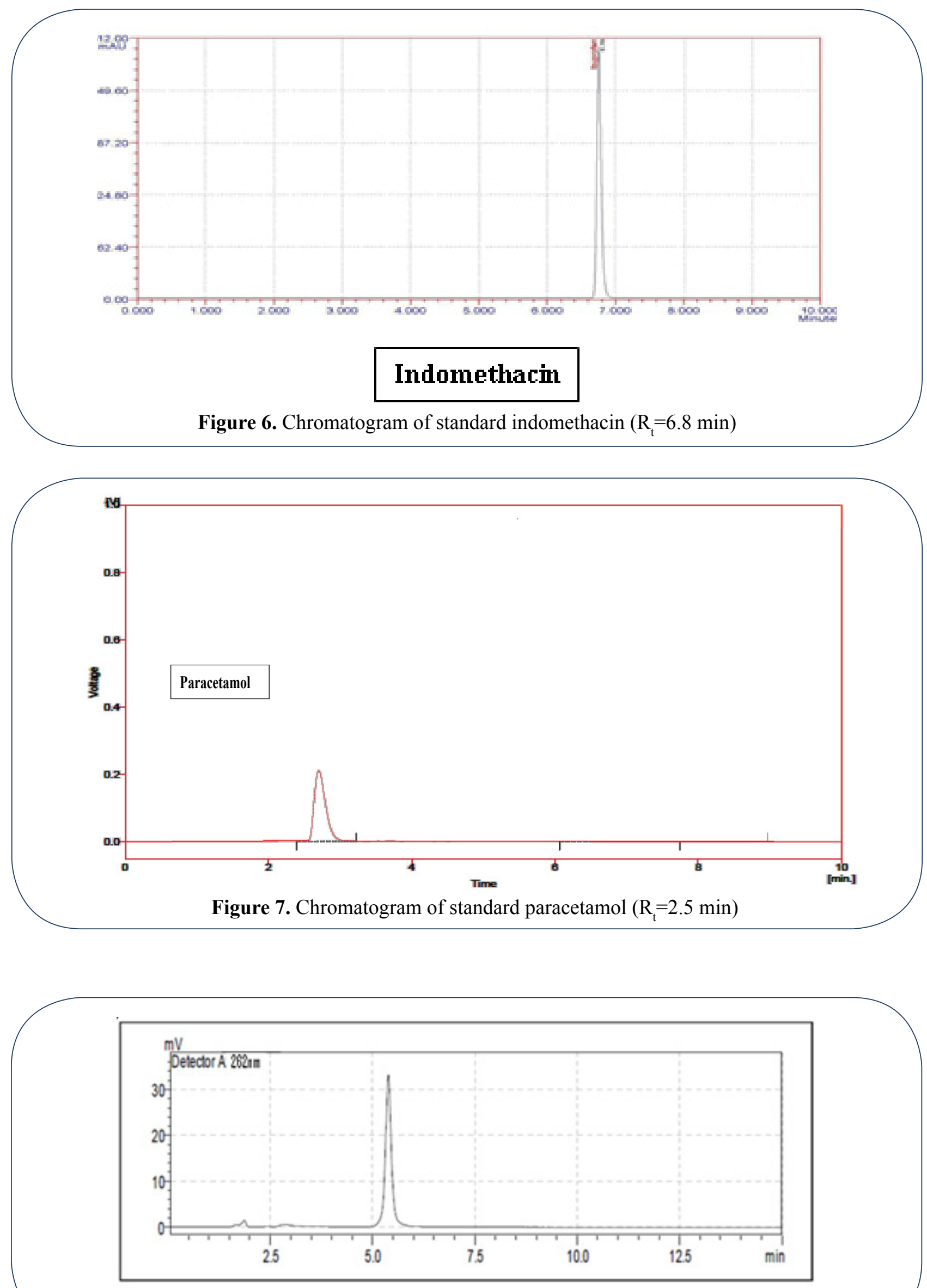

Figure 8. Chromatogram of Prodrug- $A(10 \mu \mathrm{g} / \mathrm{ml})\left(\mathrm{R}_{\mathrm{t}}=5.5 \mathrm{~min}\right)$ 

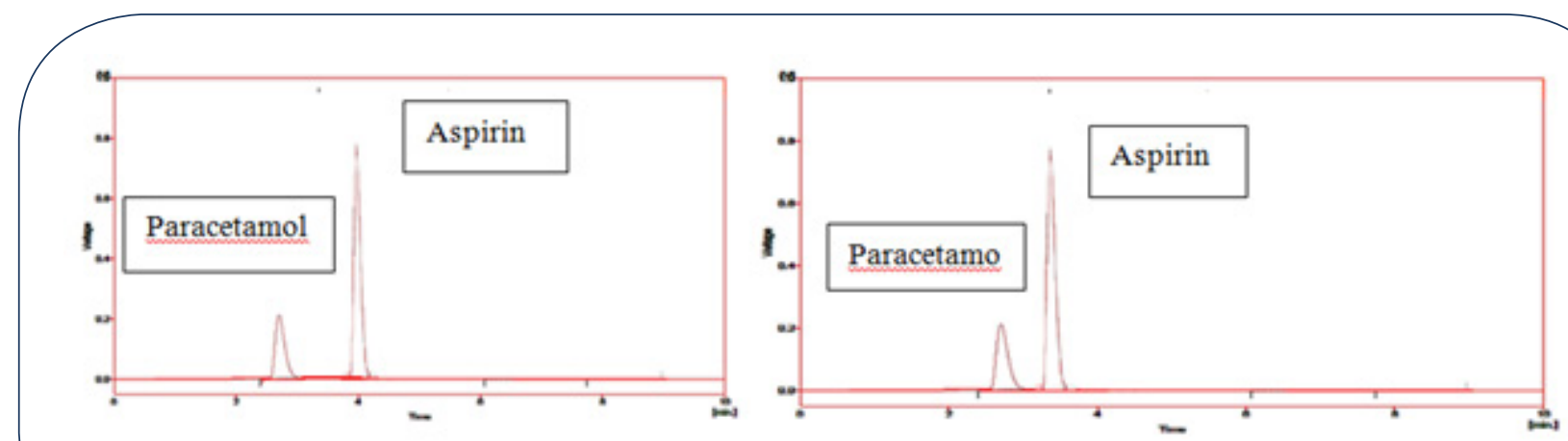

Figure 9. Chromatogram of Prodrug-A in acidic medium ( $\mathrm{HCl}: \mathrm{pH}=3.0)$ and in alkaline medium (NaOH: $\mathrm{pH}=7.5)$

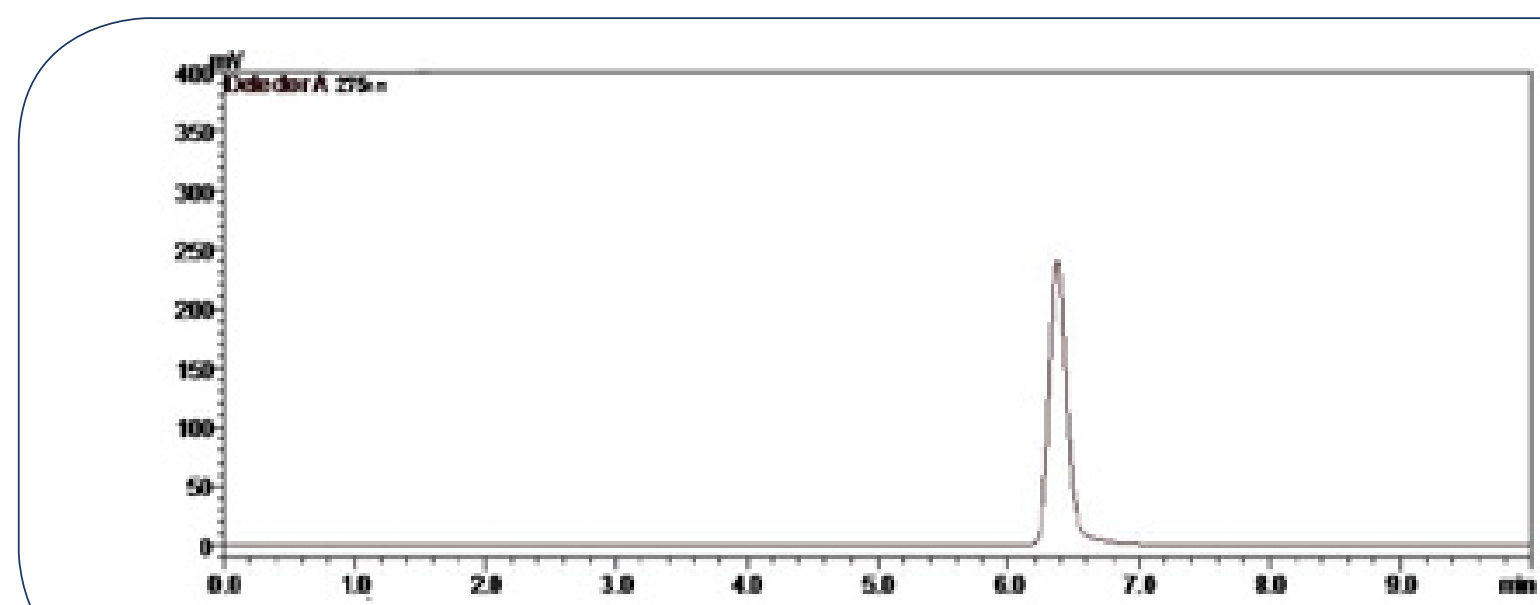

Figure 10. Chromatogram of Prodrug-B $(100 \mu \mathrm{g} / \mathrm{ml})\left(\mathrm{R}_{\mathrm{t}}=6.4 \mathrm{~min}\right)$
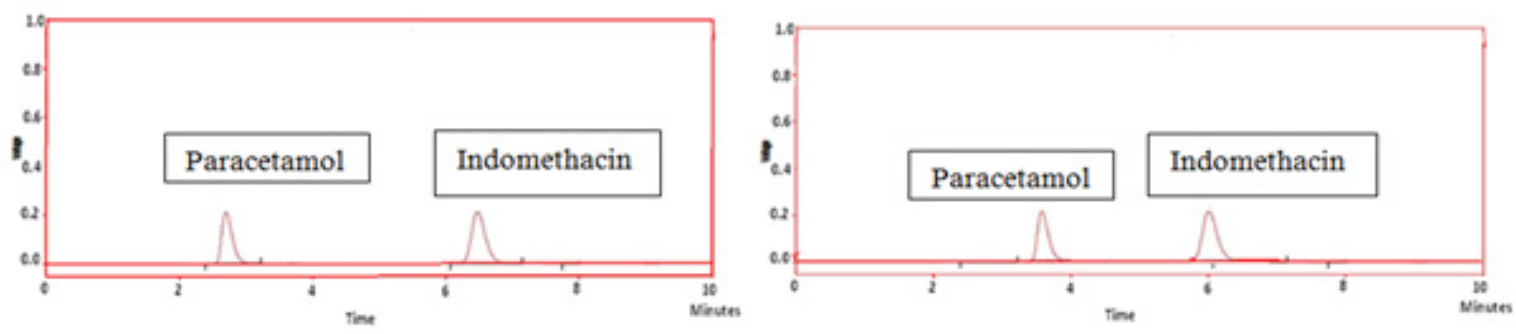

Figure 11. Chromatogram of Prodrug-B (indomethacin+paracetamol) in acidic medium $(\mathrm{HCl}: \mathrm{pH}=3.5)$ and in alkaline medium $(\mathrm{NaOH}: \mathrm{pH}=8.0)$

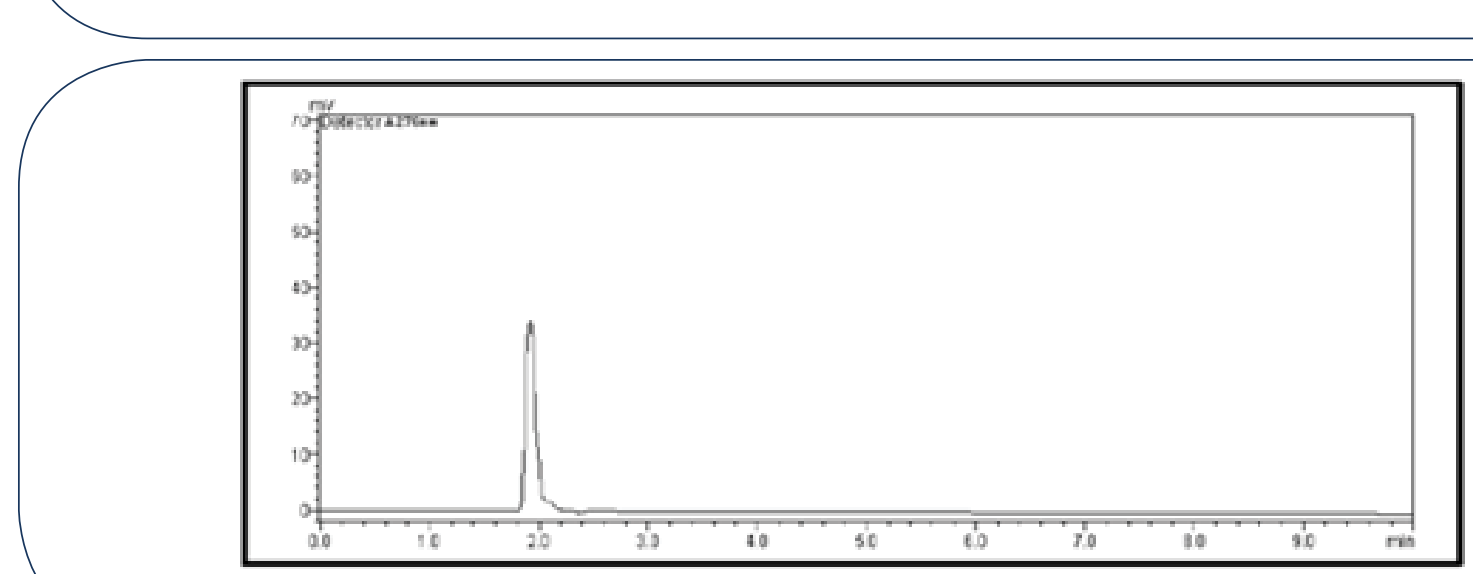

Figure 12. Chromatogram of codrug- $\mathrm{A}(30 \mu \mathrm{g} / \mathrm{ml})\left(\mathrm{R}_{\mathrm{t}}=1.8 \mathrm{~min}\right)$ 

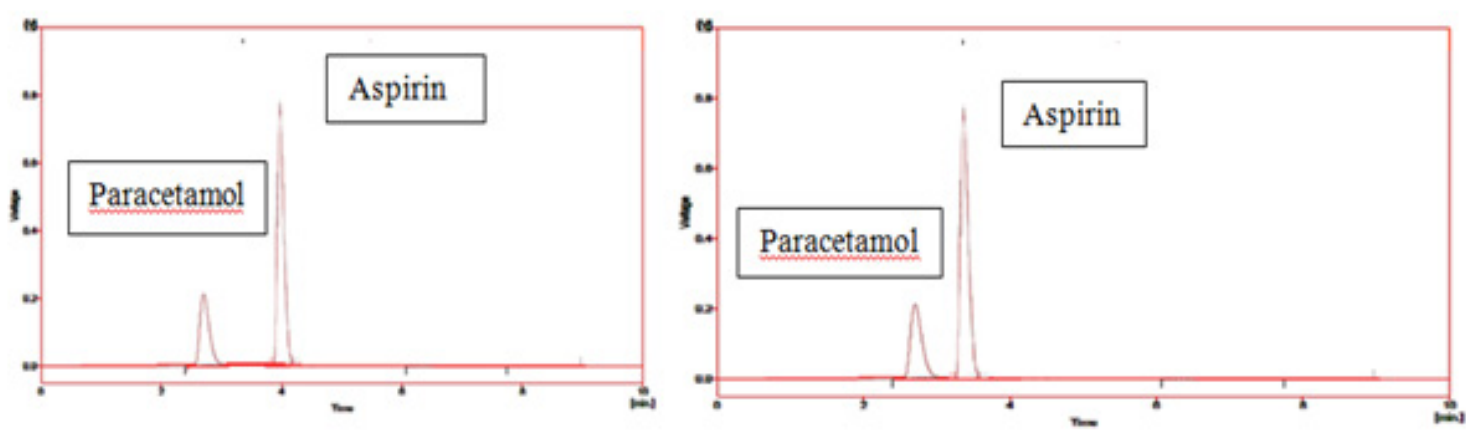

Figure 13. Chromatogram of Codrug-A in acidic medium ( $\mathrm{HCl}: \mathrm{pH}=3.0)$ and in alkaline medium (NaOH: $\mathrm{pH}=7.5)$

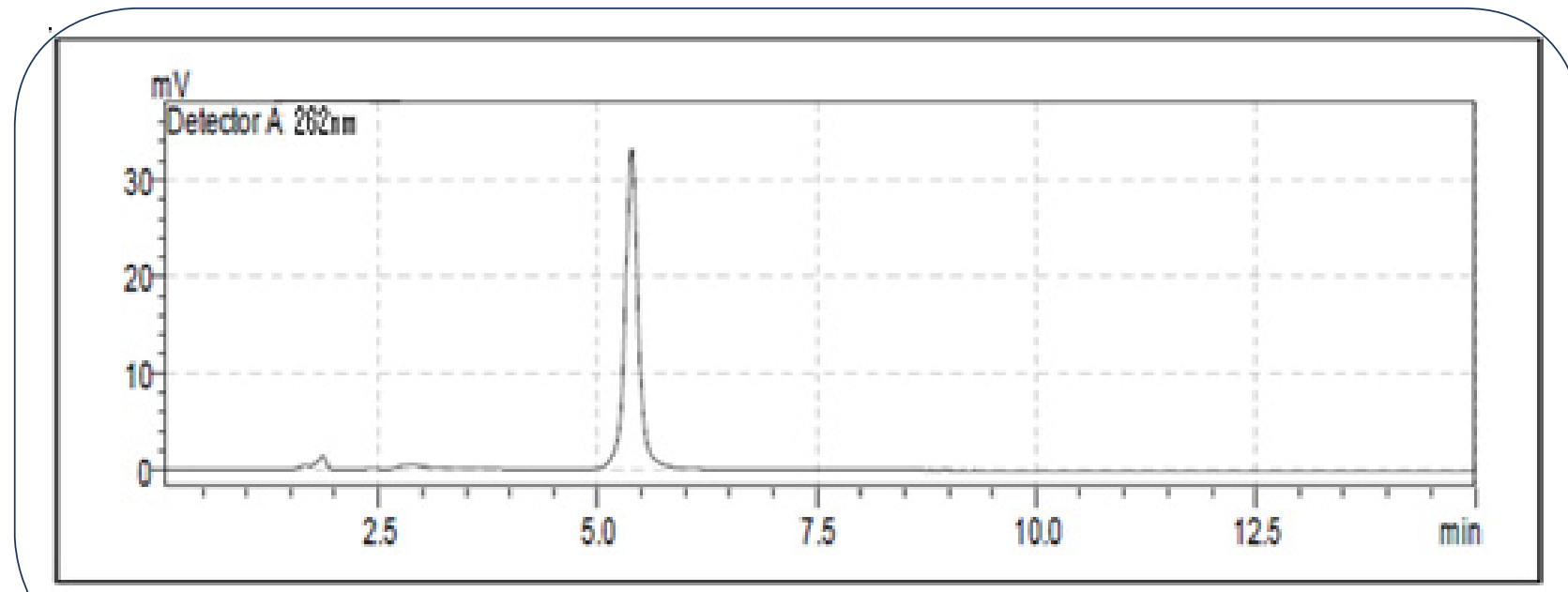

Figure 14. Chromatogram of Prodrug-B $(10 \mu \mathrm{g} / \mathrm{ml})\left(\mathrm{R}_{\mathrm{t}}=5.5 \mathrm{~min}\right)$
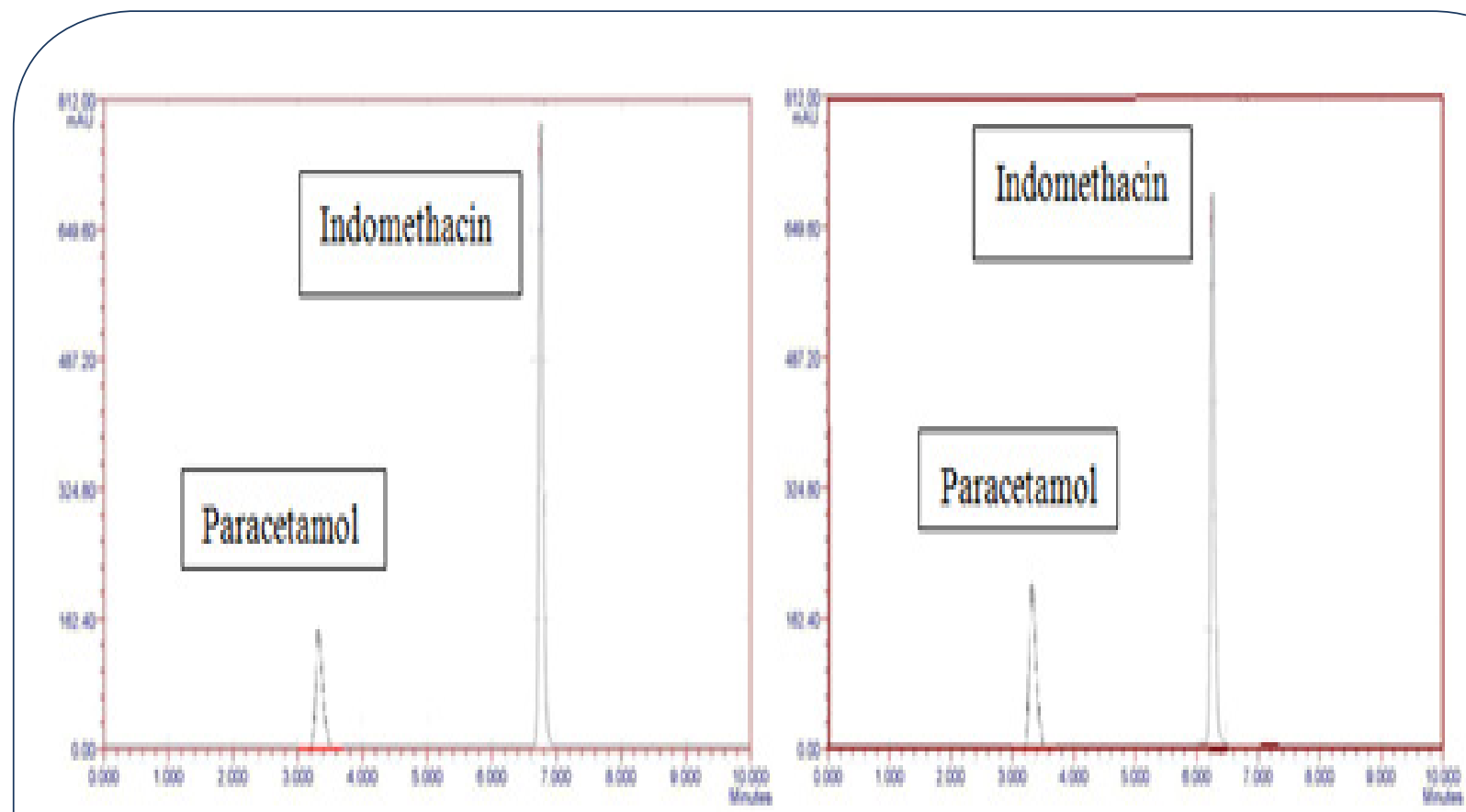

Figure 15. Chromatogram of Codrug- $\mathrm{B}$ in acidic medium $(\mathrm{HCl}: \mathrm{pH}=3.0)$ and in alkaline medium $(\mathrm{NaOH}$ : $\mathrm{pH}=7.5)$ 


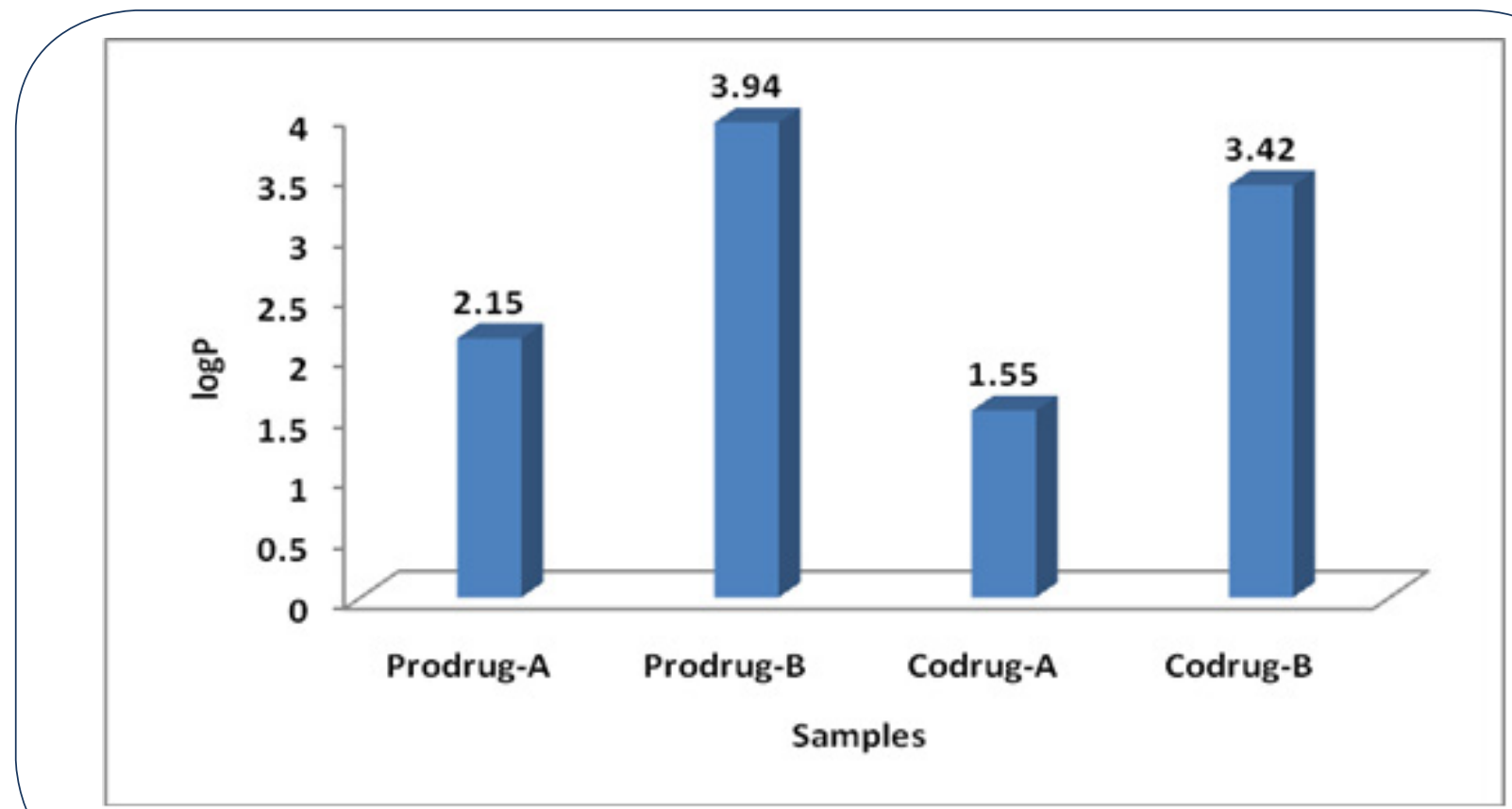

Figure 16. $\log \mathrm{P}$ profiles of prodrug and codrugs

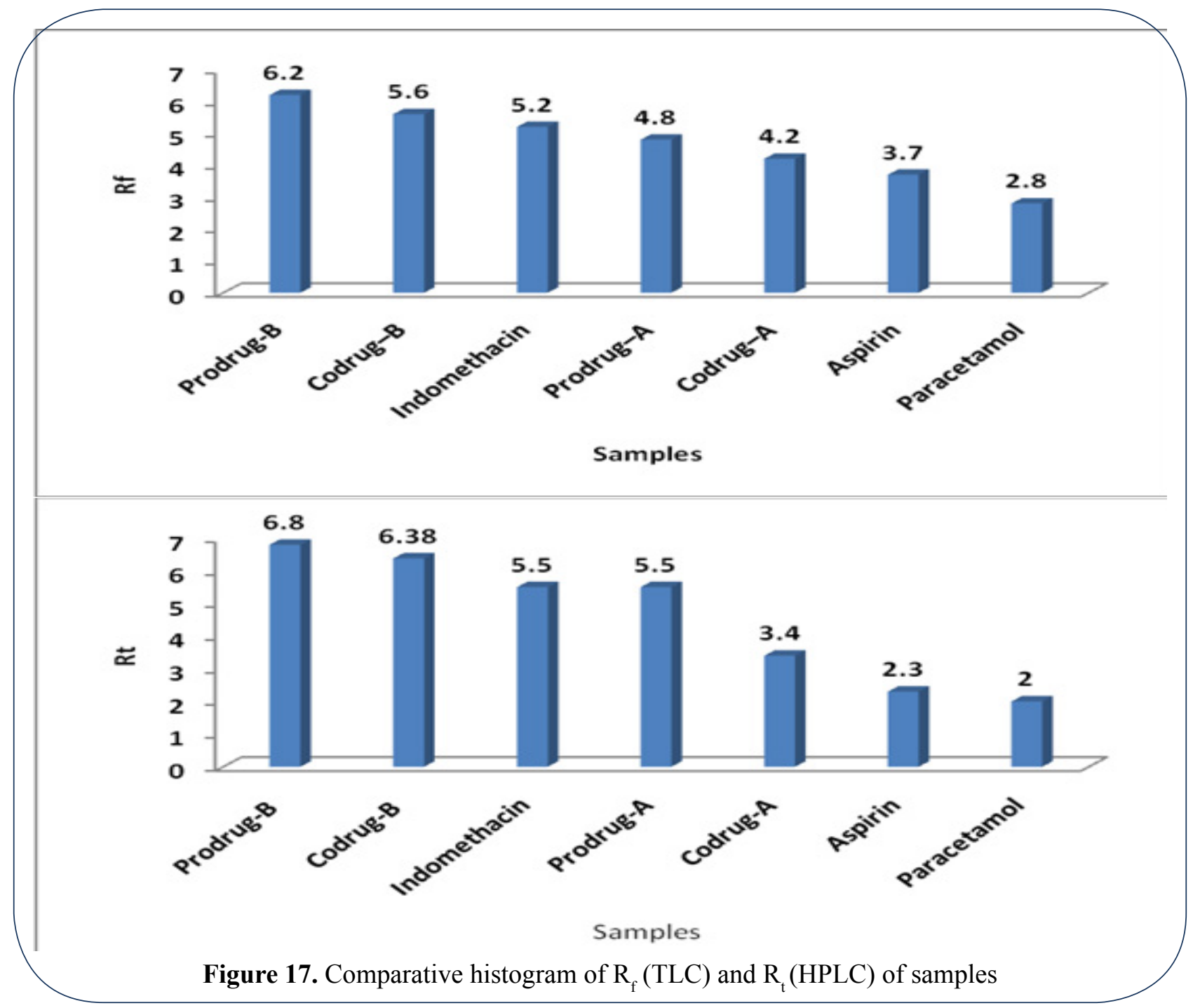

